\title{
Neodymium recovery from NdFeB magnet wastes using Primene 81R.Cyanex 572 IL by solvent extraction
}

\author{
S. Pavón ${ }^{\mathrm{a}, *}$, A. Fortuny ${ }^{\mathrm{a}}$, M.T. Coll ${ }^{\mathrm{b}}$, A.M. Sastre ${ }^{\mathrm{c}}$ \\ a Chemical Engineering Department, EPSEVG, Universitat Politècnica de Catalunya, Víctor Balaguer 1, 08800 Vilanova i la Geltrú, Spain \\ ${ }^{\mathrm{b}}$ Agri-Food Engineering and Biotechnology Department, ESAB, Universitat Politècnica de Catalunya, Esteve Terrades 8, 08860 Castelldefels, Spain \\ c Chemical Engineering Department, ETSEIB, Universitat Politècnica de Catalunya, Diagonal 647, 08028 Barcelona, Spain
}

\section{ARTICLE INFO}

\section{Keywords:}

Neodymium recovery

Counter-current process

Ionic liquid

Solvent extraction

Primene 81R.Cyanex 572 IL

\begin{abstract}
A B S T R A C T
The necessity of Rare Earth Elements (REEs) recycling is crucial to minimizing their supply risk and provide an alternative to greener technologies. Hence, the REEs recovery from NdFeB magnet wastes using cationic extractants by solvent extraction technique has been investigated in this research. Due to the difficulty in maintaining the aqueous $\mathrm{pH}$ in the industrial counter-current devices when extractants like Cyanex 272 or Cyanex 572 are used, the Primene 81R.Cyanex 572 ionic liquid has been synthesised to overcome this. 99.99\% Nd(III) recovery with a purity of $99.7 \%$ from an aqueous mixture of $\mathrm{Nd} / \mathrm{Tb} / \mathrm{Dy}$ in chloride medium, the three representative REEs present in the NdFeB magnets wastes, has been achieved after two stages counter-current extraction process using $0.30 \mathrm{M}$ of Primene 81R.Cyanex 572 ionic liquid (1:4 A:O ratio) diluted in Solvesso 100, without any aqueous $\mathrm{pH}$ conditioning.
\end{abstract}

\section{Introduction}

Rare earth permanent magnets are increasingly playing a relevant role in clean energy applications.

In fact, this sector holds first place in the priority of recycling taking into account the difficulty in finding substitutes, the critical use of REEs in magnets which are neodymium, praseodymium, dysprosium, terbium and samarium and the potential value of the waste stream (European Commission, 2014; U.S. Department of Energy, 2012). Therefore, the magnets growing tendency does not seem to be changing in the near future, because nowadays, there is a high dependence on the REEs from different sectors and applications, like the motor industry, automation, technology devices, e-mobility, renewable energies and wind power. Although prices and demand are high, only a small fraction of REEs are being recycled. In 2011, just 1\% was recycled (Tsamis and Coyne, 2015). Nevertheless, recycling and recovering these metals from urban mines is economically and environmentally beneficial because these wastes are reduced and it brings some independence from REEs producing countries.

Permanent magnets are divided into four categories: (1) Neodymium-Iron-Boron (NdFeB), (2) Samarium-Cobalt (SmCo), (3)
Ferrite and (4) Aluminium-Nickel-Cobalt (AlNiCo). The formers are stronger than the other ones and their sizes are not restricted due to brittleness problems. Thus they are more appropriate for large applications (Smith Stegen, 2015). Therefore, the NdFeB magnets are used more than the SmCo ones, and approximately 26,000 tons per year of REEs are used in the manufacture of NdFeB permanent magnets (Rare et al., 2015). Although NdFeB magnets are more expensive than ferrite and AlNiCo magnets, which are commonly used in wind turbine generators (WTGs), they can produce a higher magneto-motive force in smaller magnet sizes (Rao et al., 2017). Due to the advantages of permanent magnet generators (PMG) based on the REEs use, the average annual demand growth rate forecast for NdFeB in WTGs will increase by $10 \%$ in the 2020-2030 period (Schulze and Buchert, 2016). For this reason, it is necessary to study these magnets and find efficient separation and recovery processes.

Up to now, there are many separation and recovery processes for REEs. Among them, the solvent extraction is the most common technique using a wide range of extractants. Cyanex 272 (bis(2,4,4-trimethylpentyl)phosphinic acid, Cy272) (Liu et al., 2014), DEHPA (di-(2-ethylhexyl)phosphoric acid) and EHEHPA (2-ethylhexylphosponic acid mono-2-ethylhexyl ester, PC88A, P507) (Mohammadi et al., 2015), Cyanex 923 (mixture of trialkylphosphine oxides) (Batchu et al.,

\footnotetext{
* Corresponding author.

Email address: sandra.pavon@upc.edu (S. Pavón)
} 
2017), TBP (tributyl phosphate) (Chen et al., 2016) and the ionic liquids (Larsson and Binnemans, 2015; Chen et al., 2017) are but a few examples. Liu et al. suggest that by adding TBP into the binary mixture of Cyanex 272 and Alamine 336 a better Nd/Pr separation factor is obtained (Liu et al., 2015). The extraction of neodymium and praseodymium abilities in using different ionic liquid were investigated by Padhan and Sarangi and they proposed the Cyanex 272.Alamine 336 IL > DEHPA.Alamine 336 IL > Cyanex $272>$ DEHPA > Aliquat 336 extraction order (Padhan and Sarangi, 2017). Cyanex 572 (Cy572) is a commercial extractant that has been specially developed for the extraction and purification of REEs (CYTEC Industries Inc, 2013). It is a mixture of Cy272 and PC88A and it allows the stripping of REE using lower acid concentrations rather than using phosphonic acids due to the complex strength formed by the REEs (CYTEC Industries Inc, 2013; Quinn et al., 2015; Wang et al., 2015). Tunsu et al. reported that the separation of Yttrium and Europium from solutions of fluorescent lamp waste was successfully achieved using Cy572 (Tunsu et al., 2016). Th was recovered using Cy572 with two different processes depending on its concentration. $95 \%$ and $99.9 \%$ purity of Th were respectively obtained by Wang et al. recovering from low and high Th concentrations using different extraction, scrubbing and stripping stages (Wang et al., 2017). The extraction and separation of Heavy Rare Earth Elements (HREEs) from ion-adsorbed deposits using Cy572 was more effective than using P507; considering the stripping efficiency, the lower acid requirements and also from an environmental point of view (Wang et al., 2015).

Taking into account that $30 \%$ of the NdFeB magnets are REEs (Tunsu et al., 2015; Binnemans et al., 2013) and Nd, Dy and Tb, are critical REEs according to their supply risk and importance in clean energy markets (Tunsu et al., 2015), the current research has been focused on how to recover and separate these REEs from magnet wastes.

In order to evaluate the selectivity to separate the REEs from a mixture containing neodymium, terbium and dysprosium in chloride media, extractants such as Cyanex 272 and Cyanex 572 have been studied using the solvent extraction technique. However, extrapolating the results obtained in this study to set up an industrial separation process, it appears the difficulty in maintaining the $\mathrm{pH}$ in a counter-current process using cationic extractants, as can be seen in Eq. (1) where a possible extraction mechanism considering the dimeric form of the extractant involved in the extraction process is shown (Tunsu et al., 2016). Although there are many industrial processes, where the $\mathrm{pH}$ is controlled when cation extractants are used, this research suggests an alternative to avoid the necessity of the inter-step $\mathrm{pH}$ control using an ionic liquid as an extractant.

$M e^{3+}+3{\overline{(H A)_{2}}}_{2}{ }_{1}{\overline{M e\left(H A_{2}\right)_{3}}}^{3}+3 H^{+}$

For this reason, the investigation of Primene 81R.Cyanex IL behaviour as the extractant to selectively recover REEs from magnet wastes is promising. As shown in Eq. (2), there is no proton exchange to the aqueous phase when rare earths are extracted with this IL, and consequently, the aqueous phase $\mathrm{pH}$ is not modified after extraction.

$$
3 \overline{\mathrm{RNH}_{3}^{+} \mathrm{A}^{-}}+\mathrm{Me}^{3+}+3 \mathrm{Cl}^{-} \stackrel{\mathrm{K}_{2}}{\leftrightarrow \mathrm{MeA}_{3} \cdot 3 \mathrm{RNH}_{3}^{+} \mathrm{Cl}^{-}}
$$

According to this, the first part of the study was focused on the Cyanex choice (C272 or C572) to form the ionic liquid taking into account its selectivity HREEs/neodymium and its behaviour on the neodymium separation. When the Primene 81R.Cyanex IL was synthesized, different parameters were studied, such as contact time, $\mathrm{pH}$, ratio of IL, IL concentration and diluent used, to achieve the Nd(III) separation from a mixture of $\mathrm{Nd} / \mathrm{Tb} / \mathrm{Dy}$ using an aqueous phase concentration coincident with the real concentration of these REEs in the magnet wastes by a counter-current extraction process.

\section{Experimental}

\subsection{Reagents}

The aqueous phase solutions were prepared by dissolving $\mathrm{Nd}_{2} \mathrm{O}_{3}$ (Sigma Aldrich Ref. 228656, 99.9\%), $\mathrm{Tb}_{2} \mathrm{O}_{3}$ (Sigma Aldrich Ref. 590509, 99.99\%) and $\mathrm{Dy}_{2} \mathrm{O}_{3}$ (Sigma Aldrich Ref. 289264, 99.9\%) in hydrochloric acid. $\mathrm{NaCl}, \mathrm{NaOH}$ or $\mathrm{HCl}$ were added to adjust the $\mathrm{pH}$ and the chloride concentration. Citric acid (Sigma Aldrich Ref. 251275, 99.5\%) and hydrochloric acid were used as stripping agents. Cy272, Cy572 and Primene 81R.Cyanex 572 IL (P81R.Cy572 IL) were used as extractants. Both Cyanex extractants and P81R were kindly supplied by Cytec Canada Industries and Dow Chemical, respectively, and they were used as received. Detailed specifications of these extractants are summarized in Table 1. Kerosene, from Sigma-Aldrich, was used mainly in the majority of the experiments as a diluent. Toluene (methylbenzene), Cumene (isopropylbenzene), Solvesso 100 (a mixture of alkyl $\left(\mathrm{C}_{3}\right)$-benzenes) and Solvesso 200 (a mixture of alkyl $\left(\mathrm{C}_{4}-\mathrm{C}_{7}\right)$-benzenes) were also used to investigate the effects of the diluent on the extraction. ExxonMobil supplied both Solvesso diluents and they were used as received.

\subsection{Primene $81 R \cdot$ Cyanex 572 IL preparation}

P81R.Cy572 IL is a home-made ionic liquid that was produced by mixing these two commercial extractants, Primene 81R (primary t-alkyl amine, P81R) and Cy572. In order to prepare the P81R.Cy572 IL, stoichiometric quantities of P81R and Cy572 were mixed in kerosene as can be seen in Eq. (3) below.

$$
2 \overline{R N H_{2}}+\overline{(H A)}_{2} \leftrightarrow 2 \overline{R N H_{3}^{+} A^{-}}
$$

\subsection{Solvent extraction procedure}

For the extraction experiments, the concentration of $\mathrm{Nd}(\mathrm{III}), \mathrm{Tb}(\mathrm{III})$ and Dy(III) in the aqueous phase was $1 \mathrm{~g} \mathrm{dm}^{-3}$ of each metal (or specified concentration) in $4 \mathrm{M} \mathrm{Cl}^{-} \cdot 10 \mathrm{~cm}^{3}$ of this aqueous phase were equilibrated at room temperature $\left(20 \pm 2{ }^{\circ} \mathrm{C}\right)$ with an equal volume of organic phase in a separatory funnel using a horizontal mechanical shaker (SBS Mechanical Shaker) at $140 \mathrm{rpm}$ for $10 \mathrm{~min}$, until the equilibrium was achieved. In order to evaluate the effect of the citric acid and $\mathrm{HCl}$ as stripping agents, $5 \mathrm{~cm}^{3}$ aliquots of the organic phase were placed in two new separatory funnels to make the stripping process using citric acid $1 \mathrm{M}$ and $\mathrm{HCl} 1.2 \mathrm{M}$. After the separation phases, the con-

Table 1

\begin{tabular}{|c|c|c|c|c|}
\hline Commercial name & $\begin{array}{l}\text { Content } \\
\%\end{array}$ & $\begin{array}{l}\text { Density } \\
\mathrm{kg} \cdot \mathrm{m}^{-3}\end{array}$ & $\begin{array}{l}\text { Viscosity } \\
\left(25^{\circ} \mathrm{C}\right) \\
\mathrm{mPa} \cdot \mathrm{s}\end{array}$ & $\begin{array}{l}\text { Av. } \\
\text { Mol. } \\
\text { Weight } \\
\text { g. } \mathrm{mol}^{-1}\end{array}$ \\
\hline $\begin{array}{l}\text { Cyanex } 272 \\
\text { (CYTEC } \\
\text { Industries Inc, } \\
2008 \text { ) }\end{array}$ & 85 & 920 & 14.2 & $290^{\mathrm{a}}$ \\
\hline $\begin{array}{l}\text { Cyanex } 572 \\
\text { (CYTEC } \\
\text { Industries Inc, } \\
\text { 2013) }\end{array}$ & 100 & 933 & $<50$ & $310^{\mathrm{a}, \mathrm{b}}$ \\
\hline Primene 81R & 100 & 860 & $2.58^{c}$ & $191^{\mathrm{b}}$ \\
\hline
\end{tabular}

Physical properties of Cy272, Cy572 and P81R.

a As a monomer.

b Experimental data by potentiometric titration in water/ethanol.

c Viscosity data by Rohm HA\&AS (ROHM HA\&AS, 1961). 
centration of the REEs in the aqueous phase was determined by atomic emission spectrometry using a 4100MP AES System (Agilent Technologies) with an analytical error $\leq 5 \%$. A triplicate test was made.

Extraction efficiency (\%E), stripping efficiency (\%S), distribution ratio (D) and separation factor ( $\beta$ ) are defined in Eqs. (4)-(7) to evaluate the results.

$\% E=\frac{[M e]_{a q, 0}-[M e]_{a q, e q}}{[M e]_{a q, 0}} \times 100$

$\% S=\frac{[M e]_{a q, s}}{[M e]_{\text {org }}} \times 100$

$D_{M e}=\frac{[M e]_{o r g}}{[M e]_{a q}}$

$\beta_{1,2}=\frac{D_{M e 1}}{D_{M e 2}}$

where $[\mathrm{Me}]_{a q, 0}$ and $[\mathrm{Me}]_{a q, e q}$ refer to the initial and equilibrium concentration of rare earth in the aqueous phase, $[\mathrm{Me}]_{a q, s}$ is the equilibrium concentration of REE in the stripping phase and $[\mathrm{Me}]_{\text {org }}$ is the concentration of REE in the loaded organic phase.

\subsection{Extraction mechanism}

The metal extraction mechanism was investigated taking into account Eq. (1) using Cy272 or Cy572, Eq. (2) in the case of P81R.Cy572 IL and irrespective of the REEs speciation. In this extraction mechanism investigation, the equilibrium constants can be written as follows in Eq. (8) and Eq. (9) corresponding to the equilibrium equations Eq. (1) and Eq. (2), respectively:

$K_{1}=\frac{\left[\overline{M e\left(H A_{2}\right)_{3}}\right] \cdot\left[H^{+}\right]^{3}}{\left[M e^{3+}\right] \cdot\left[\overline{(H A)_{2}}\right]^{3}}$

$$
K_{2}=\frac{\overline{\left[\mathrm{MeA}_{3} \cdot 3 \mathrm{RNH}_{3}^{+} \mathrm{Cl}^{-}\right]}}{\left[M e^{3+}\right] \cdot\left[\overline{R N H_{3}^{+} A^{-}}\right]^{3} \cdot\left[C l^{-}\right]^{3}}
$$

Replacing the distribution ratio D (Eq. (6)) on Eq. (8) and Eq. (9):

$$
\begin{aligned}
& K_{1}=\frac{D \cdot\left[\mathrm{H}^{+}\right]^{3}}{\left[\overline{(\mathrm{HA})_{2}}\right]^{3}} \\
& K_{2}=\frac{D}{\left[\overline{R N H_{3}^{+} A^{-}}\right]^{3} \cdot\left[\mathrm{Cl}^{-}\right]^{3}}
\end{aligned}
$$

Applying logarithms on Eq. (10) and Eq. (11), the linearized Eq. (12) and Eq. (13) were obtained. $\log D=\log K_{1}+3 \log \left[{\overline{(H A)_{2}}}_{2}\right]-3 \log \left[H^{+}\right]$

$\log \mathrm{D}=\log \mathrm{K}_{2}+3 \log \left[\overline{\mathrm{RNH}_{3}^{+} A^{-}}\right]+3 \log \left[\mathrm{Cl}^{-}\right]$

According to these equations, plotting $\log D+3 \log \left[\mathrm{H}^{+}\right]$vs. $\log \left[\overline{(H A}_{2}\right]$ and $\log D-3 \log \left[\mathrm{Cl}^{-}\right]$vs. $\log \left[\overline{\mathrm{RNH}_{3}^{+} A^{-}}\right.$, a slope equal to 3 should be observed if the stoichiometry metal-ligand matches with the proposed mechanism. Additionally, a slope of 3 should be obtained plotting $\log D-3 \log \left[\overline{(H A}_{2}\right]$ vs. $-\log \left[H^{+}\right]$, meaning that three protons are involved in the suggested extraction process.

The equations have been written in terms of hydrogen ion concentration, since the $\mathrm{pH}$ measurements are not accurate under the highly acidic conditions studied.

\subsection{Counter-current extraction procedure}

The counter-current process was carried out using separatory funnels in which $5 \mathrm{~cm}^{3}$ of the aqueous phase and $20 \mathrm{~cm}^{3}$ of the organic phase were introduced. The metal concentrations in the feed solution corresponded to the representative REE concentrations on magnet wastes. Therefore, the aqueous phase was a mixture containing 9.00, 0.50 and $2.55 \mathrm{~g} \mathrm{dm}^{-3}$ of $\mathrm{Nd}(\mathrm{III}), \mathrm{Tb}(\mathrm{III})$ and $\mathrm{Dy}(\mathrm{III})$, respectively (Binnemans et al., 2013; Sasai and Shimamura, 2016; Yang et al., 2017) at an initial $\mathrm{pH} 0.10$ and $4 \mathrm{M} \mathrm{Cl}^{-}$medium. The organic phase was $0.30 \mathrm{M}$ of P81R.Cy572 IL. The process separation started with 2 separatory funnels, named funnel 1 and funnel 2, with an aqueous to organic (A/O) phase ratio $1: 4$, then shaken for $10 \mathrm{~min}$. When both phases were separated, the steps described below were followed:

1. Take a new separatory funnel, the number $2^{\prime}$, and a fresh organic phase is introduced.

2. Remove the aqueous phase from the separatory funnel number 2 as a sample.

3. Put the raffinate from the funnel 1 into funnel 2'.

4. A fresh aqueous phase in the separatory funnel 2 is introduced.

5. Take out the funnel 1 and the other two funnels (funnel 2 and 2 ' will be relabelled as 1 and 2, respectively) are shaken for $10 \mathrm{~min}$.

This procedure was repeated (11 times) until the REE concentrations were constant, meaning that the process was stabilized. In order to check the process stabilization, the remaining organic phases were stripped. Then, $\mathrm{Nd}(\mathrm{III}), \mathrm{Tb}(\mathrm{III})$ and $\mathrm{Dy}(\mathrm{III})$ concentrations in the aqueous phases were determined.

\section{Results and discussion}

\subsection{Cyanex 272 and Cyanex 572}

\subsubsection{Effect of the contact time}

The extraction of $\mathrm{Nd} / \mathrm{Tb} / \mathrm{Dy}$ by Cy272 and Cy572 and the stripping of these REEs by $\mathrm{HCl} 1.2 \mathrm{M}$ and citric acid $1 \mathrm{M}$ were investigated at specific contact times. The results showed that the equilibrium was achieved within $5 \mathrm{~min}$ and the extraction and stripping percentages were unchanged while extending the mixing time. Consequently, a fixed mixing time of $10 \mathrm{~min}$ was used in all the subsequent experiments to ensure complete equilibrium.

\subsubsection{Effect of $p H$}

The $\mathrm{pH}$ is a critical parameter to separate REEs using cationic extractants. As is seen in Fig. 1a and Fig. 1b, the extraction of $\mathrm{Nd}(\mathrm{III})$, 


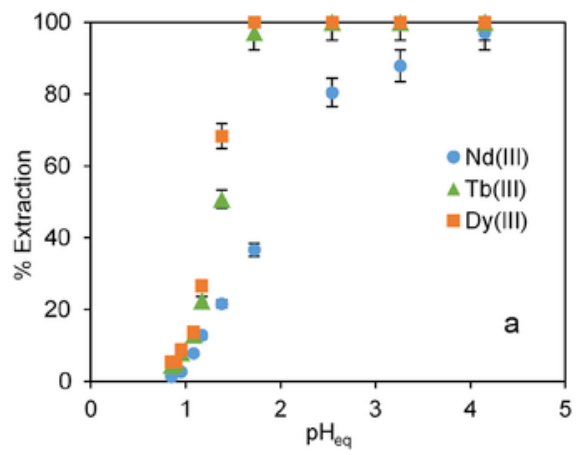

Fig. 1. Effect of the equilibrium $\mathrm{pH}$ on the extraction of $1 \mathrm{gdm}^{-3}$ REEs in $4 \mathrm{M} \mathrm{Cl}^{-}$

$\mathrm{Tb}(\mathrm{III})$ and Dy(III) increased due to the increasing equilibrium $\mathrm{pH}$. The appropriate $\mathrm{pH}$ ranges to achieve the REEs separation are from 1.4 to 1.8 using Cy272 (Fig. 1a) and from 0.4 to 1.3 using Cy572 (Fig. $1 \mathrm{~b})$; because, in these ranges, the bigger selectivity values of HREEs/ neodymium were obtained (Pavon et al., 2017).

The contrasting plots of $\log D-3 \log \left[\overline{(H A}_{2}\right]$ vs. $-\log \left[H^{+}\right]$(see Fig. S1.a and $\mathrm{b}$ in the supplementary material) allow us to determine the slope values for each metal using both Cyanex. The obtained results are consistent with the proposed extraction mechanism in Eq. (1). Although the values of the Nd(III) slopes for both extractants are less than 2.50, the slope values of terbium and dysprosium indicate that the extraction of these metals followed a cationic exchange mechanism and three protons are involved in the extraction process within our experimental ranges (Eq. (1)). The extraction process result obtained is also in accordance with references Tunsu et al. (2016) and Huang and Tanaka, (2010).

\subsubsection{Effect of the extractant concentration}

The effect of the extractant concentration was investigated in the range 5\%-20\% range (v/v) using Cy272 (0.14-0.54M) and Cy572 $(0.15-0.60 \mathrm{M})$ as extractants (Fig. 2a and Fig. 2b) and kerosene as diluent. The concentration of each REE in the mixture was $1 \mathrm{gdm}^{-3}$ in $4 \mathrm{M}$ $\mathrm{Cl}^{-}$medium. The initial $\mathrm{pH}$ was set to 3.50 for both extractants and the stripping agent used was $\mathrm{HCl} 1.2 \mathrm{M}$.

Although the results showed that the percentages of REEs extraction increases when the extractant concentration increases, the rise in the extracted Nd(III) was less than the other two REEs. Even though the equilibrium pHs decreased when the concentration of the extractants increased in all the cases, the equilibrium $\mathrm{pH}$ values using Cy572 was less than when Cy272 was used, being in agreement to the obtained extraction percentages (Fig. 2a and b). This fact accords with the extraction mechanism for cationic extractants depicted previously in Eq. (1).

Because the neodymium was not extracted using Cy272 throughout the studied range, $0.54 \mathrm{M}$ was chosen since the HREEs extraction rate

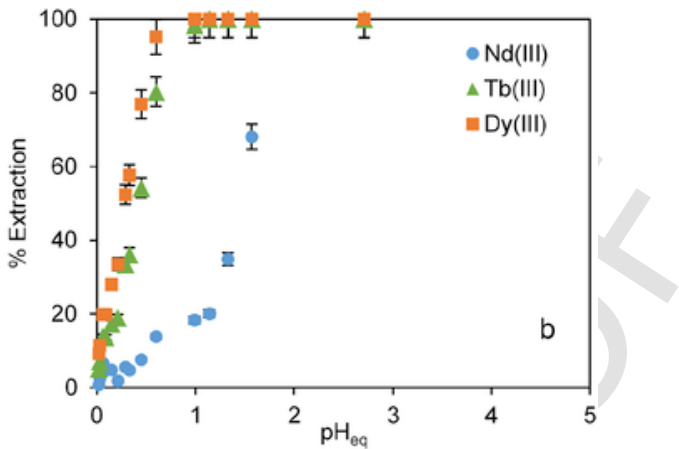

(triplicate test). a) Cy272 10\% (v/v) in kerosene b) Cy572 10\% (v/v) in kerosene.

was the highest. This Nd(III) behaviour was also observed using the lowest $(0.15 \mathrm{M}) \mathrm{Cy} 572$ concentration. In order to separate Nd(III) from the mixture, $0.30 \mathrm{M}$ was decided using Cy572 due to their highest selectivity values in Table 2 .

With the aim of investigating the extraction reaction stoichiometry of both Cyanex, the $\log \mathrm{D}+3 \log \left[\mathrm{H}^{+}\right]$vs. $\log \left[\overline{(H A}_{2}\right]$ presented in (Fig. S2. $\mathrm{a}$ and $\mathrm{b}$ in the supplementary material). In these plots, Cy272 and Cy572 are considered as dimers according to Eq. (1) and both plots show linear tendencies using both Cyanex. Due to the non-extraction of the neodymium using Cy272, the $D_{N d}$ cannot be calculated and therefore no slope is presented. The slope values were 2.76 and 2.85 for $\mathrm{Tb}(\mathrm{III})$ and Dy(III), respectively. In the same way, the obtained slope values using Cy572 were 3.37, 3.36 and 3.30. This accords with the extraction mechanism depicted in Eq. (1).

\subsubsection{Effect of the chloride concentration in the aqueous feed}

In order to compare the chloride concentration effect using both extractants, this was investigated in the $0.10-4 \mathrm{M}$ concentration range. The aqueous phase contained $1 \mathrm{~g} \mathrm{dm}^{-3}$ of each metal at initial $\mathrm{pH}$ 3.50. The extractant concentrations used were $0.54 \mathrm{M}$ and $0.30 \mathrm{M}$ for Cy272 and Cy572, respectively.

It can be observed from the results in Fig. 3 that there is an inversely proportional relationship between the percentage of REEs extraction and the $\mathrm{Cl}^{-}$concentration. These results can be explained according to the hypothesis that the $\mathrm{Me}^{3+}$ is the extracted species. If the $\mathrm{MeCl}^{2+}, \mathrm{MeCl}_{2}{ }^{+}$or $\mathrm{MeCl}_{3}$ species were produced, consistently with Eq. (14)-(16), less $\mathrm{Me}^{3+}$ would have been extracted and consequently, the extraction would decrease, as is depicted in Eq. (1).

$$
\mathrm{Me}^{3+}+\mathrm{Cl}^{-} \leftrightarrow \mathrm{MeCl}^{2+}
$$
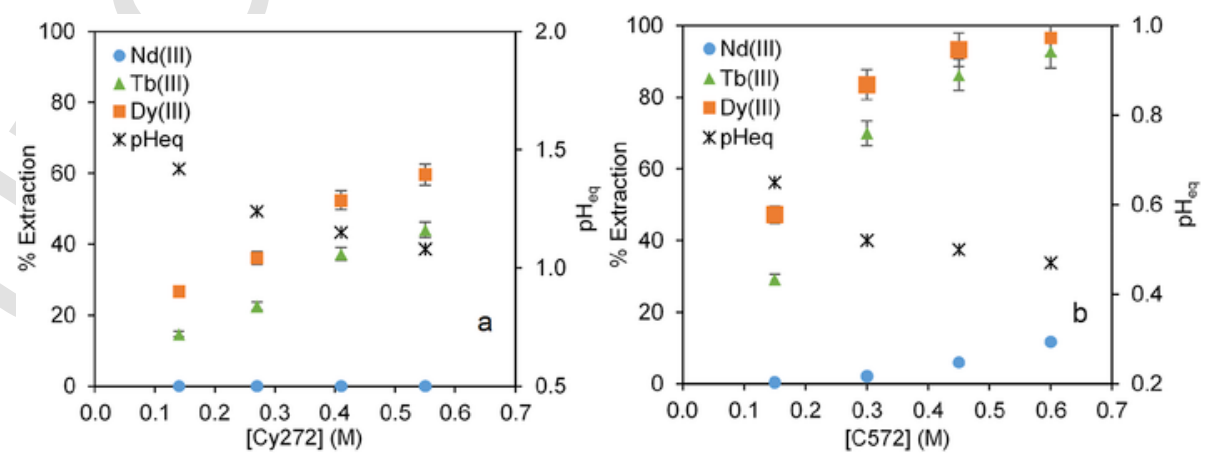

Fig. 2. Effect of extractant concentration of $1 \mathrm{~g} \mathrm{dm}^{-3}$ of REEs at initial $\mathrm{pH} 3.50$ in $4 \mathrm{M} \mathrm{Cl}^{-}$(triplicate test). Diluent: kerosene a) Effect of [Cy272]. b) Effect of [Cy572]. 
Table 2

Separation studies of Nd/Tb/Dy using different concentrations of Cy572.

\begin{tabular}{llllll}
\hline$[\mathrm{Cy} 572](\mathrm{M})$ & $\mathrm{D}_{\mathrm{Nd}}$ & $\mathrm{D}_{\mathrm{Tb}}$ & $\mathrm{D}_{\mathrm{Dy}}$ & $\beta_{\mathrm{Dy} / \mathrm{Nd}}$ & $\beta_{\mathrm{Tb} / \mathrm{Nd}}$ \\
\hline 0.15 & 0.00 & 0.41 & 0.89 & 192 & 89 \\
0.30 & 0.02 & 2.3 & 5.1 & 237 & 109 \\
0.45 & 0.06 & 6.3 & 13.8 & 217 & 99 \\
0.60 & 0.13 & 12.7 & 28.1 & 211 & 97 \\
\hline
\end{tabular}

$\mathrm{MeCl}^{2+}+\mathrm{Cl}^{-} \leftrightarrow \mathrm{MeCl}_{2}^{+}$

$$
\mathrm{MeCl}_{2}^{+}+\mathrm{Cl}^{-} \leftrightarrow \mathrm{MeCl}_{3}
$$

The $\mathrm{Cl}^{-}$influence order on the extraction is $\mathrm{Nd}(\mathrm{III})>\mathrm{Tb}(\mathrm{III})>$ and Dy(III) in the studied chloride range. This behaviour can be associated with bigger metal complex formation constants in the same order as mentioned above. Although the extraction decreasing tendency is the same using both extractants, it is more accentuated using Cy572 rather than Cy272. That is why the best optimal range to separate $\mathrm{Nd}(\mathrm{III})$ from the mixture is considered to be from $2 \mathrm{M}$ up to $4 \mathrm{M}$ of chlorides.

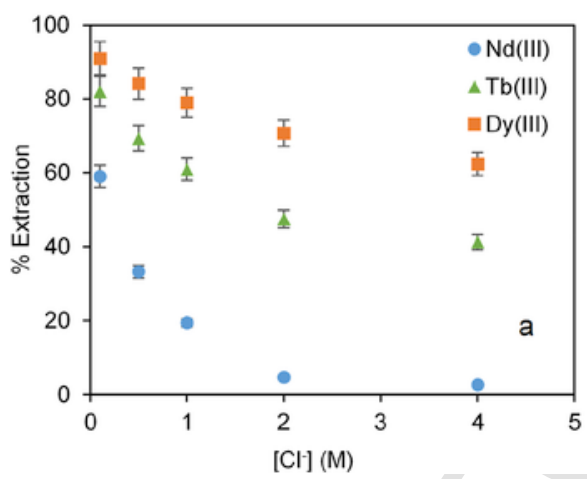

According to all the aforesaid, and with the aim of achieving a low extraction yield for neodymium and, simultaneously, achieving greater selectivity values in reference to terbium and dysprosium, $4 \mathrm{M} \mathrm{Cl}^{-}$concentration has been chosen (Table 3).

\subsubsection{Effect of the different stripping agents}

The loaded organic phases obtained in the previous experiments described in section 3.1.3 and 3.1.4 were used to investigate the effect of $\mathrm{HCl} 1.2 \mathrm{M}$ and citric acid $1 \mathrm{M}$ as stripping solutions. They have been chosen due to the acidic character in promoting the extraction process as is written in Eq. (1). As is shown in Fig. 4, the stripping percentage using hydrochloric acid $1.2 \mathrm{M}$ as the stripping agent for $\mathrm{Tb}$ (III) and $\mathrm{Dy}(\mathrm{III})$ is around to $80 \%$ for both extractants. Neodymium data is not included in Fig. 4 a because the metal was not extracted using Cy272 in the whole range of extractant concentrations, and so it is not considered for stripping in this case.

The main differences between Cy272 and Cy572 appear when citric acid $1 \mathrm{M}$ is used as the stripping agent. In this case, metals are stripped from organic phase containing Cy272 (Fig. 4 a and Fig. S3.a in the supplementary material) and not from Cy572 (Fig. S3.a and Fig. S3.b in the supplementary material). It may be due to the complexing effect of

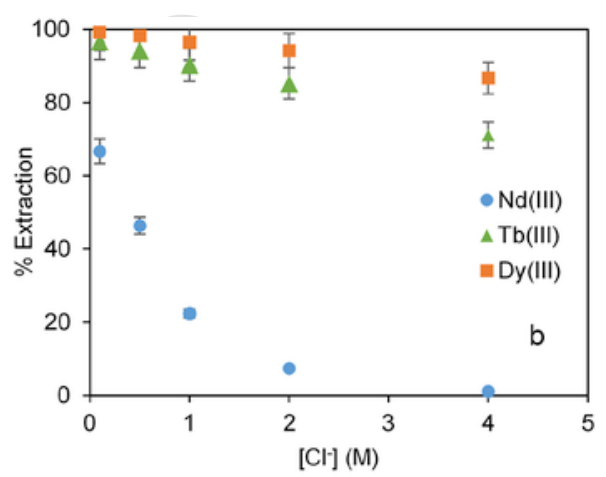

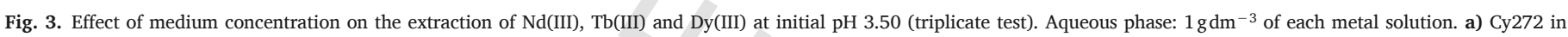
kerosene. b) Cy572 in kerosene.

Table 3

Separation studies of $\mathrm{Nd} / \mathrm{Tb} / \mathrm{Dy}$ using different $\mathrm{Cl}^{-}$concentrations.

\begin{tabular}{|c|c|c|c|c|c|c|c|c|c|c|}
\hline \multirow[t]{2}{*}[\mathrm{Cl}^{-}]{$(\mathrm{M})$} & \multicolumn{5}{|c|}{ Су272 } & \multicolumn{5}{|c|}{ Cy572 } \\
\hline & $\mathrm{D}_{\mathrm{Nd}}$ & $\mathrm{D}_{\mathrm{Tb}}$ & $\mathrm{D}_{\text {Dy }}$ & $\beta_{\mathrm{Dy} / \mathrm{Nd}}$ & $\beta_{\mathrm{Tb} / \mathrm{Nd}}$ & $\mathrm{D}_{\mathrm{Nd}}$ & $\mathrm{D}_{\mathrm{Tb}}$ & $\mathrm{D}_{\text {Dy }}$ & $\beta_{\mathrm{Dy} / \mathrm{Nd}}$ & $\beta_{\mathrm{Tb} / \mathrm{Nd}}$ \\
\hline 0.10 & 1.72 & 1.81 & 3.85 & 2.24 & 1.05 & 2.00 & 28.7 & 129 & 64.9 & 14.2 \\
\hline 0.50 & 0.69 & 1.11 & 2.24 & 3.24 & 1.61 & 0.86 & 15.6 & 57.8 & 66.9 & 18.1 \\
\hline 1.00 & 0.26 & 0.76 & 1.50 & 5.86 & 2.96 & 0.29 & 8.92 & 27.0 & 93.8 & 30.9 \\
\hline 2.00 & 0.08 & 0.46 & 1.09 & 14.5 & 6.15 & 0.08 & 5.48 & 16.2 & 201 & 68.4 \\
\hline 4.00 & 0.02 & 0.28 & 0.61 & 26.1 & 11.8 & 0.01 & 2.44 & 6.42 & 597 & 227 \\
\hline
\end{tabular}
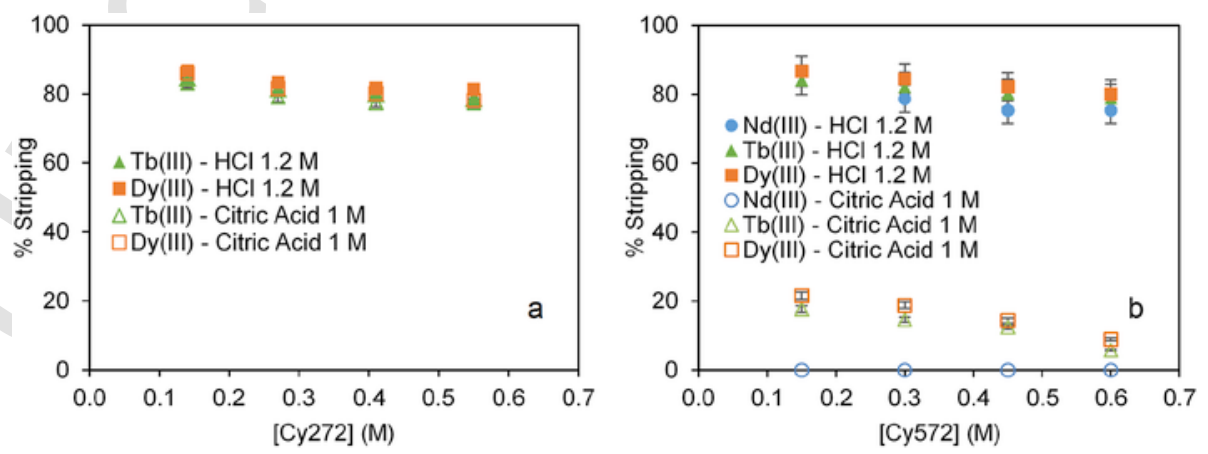

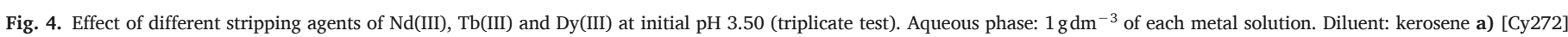
effect. b) [Cy572] effect. 
citric acid which compensates its lack of acidity. To prove it, a solution of $\mathrm{HCl} 0.01 \mathrm{M}$ was prepared with the same $\mathrm{pH}$ as the $1 \mathrm{M}$ solution of citric acid ( $\mathrm{pH} 2$ ) and no stripping of any REEs was obtained using both Cyanex. Therefore, citric acid mainly strips due to its complexing effect.

The results show that to achieve a complete stripping for both extractants using $\mathrm{HCl} 1.2 \mathrm{M}$, two stages will be required or the $\mathrm{HCl}$ concentration would have to be increased (Panda et al., 2015). As already noted previously, the optimum stripping agent to achieve a good stripping is $\mathrm{HCl} 1.2 \mathrm{M}$ for both extractants while citric acid $1 \mathrm{M}$ could be also used in the case of Cy272.

\subsection{Primene $81 R \cdot$ Cyanex $572 \mathrm{IL}$}

Even though good separation factors of $\mathrm{Dy} / \mathrm{Nd}$ and $\mathrm{Tb} / \mathrm{Nd}$ were obtained using both Cyanex, more than one stage is required to achieve a complete neodymium separation from the mixture of $\mathrm{Nd} / \mathrm{Tb} / \mathrm{Dy}$ in $4 \mathrm{M}$ $\mathrm{Cl}^{-}$. From an industrial separation process scale-up point of view, this fact makes the previous conditioning of the $\mathrm{pH}$ in the successive extraction stages necessary.

In this sense, the use of an extractant like P81R.Cyanex IL is essential in order to avoid a proton exchange during the extraction process. Comparing the results of Cy272 and Cy572, the HREEs selectivity value is better when Cy572 is used. The amount of Cy572 necessary to achieve higher values of separation factors is also less than using Cy272. Consequently, Cy572 has been chosen to be used in the P81R.Cy572 ionic liquid.

\subsubsection{Effect of the contact time}

Following the procedure previously mentioned in 3.2, the extraction and the stripping using $\mathrm{HCl} 4 \mathrm{M}$ were investigated at specific contact times; and within $5 \mathrm{~min}$, the equilibrium was achieved. In order to make sure that equilibrium was completely achieved, a $10 \mathrm{~min}$ of shaking time was utilised.

\subsubsection{Effect of $p H$}

Although the IL is a mixture of P81R and Cy572, its behaviour -when combined-could be different compared to its individual components (Liu et al., 2014). To study the $\mathrm{pH}$ effect on the $\mathrm{Nd} / \mathrm{Tb} / \mathrm{Dy}$ extraction using the P81R.Cy572 IL diluted in kerosene, the extraction curves using $0.30 \mathrm{M}$ of IL and $1 \mathrm{~g} \mathrm{dm}^{-3} \mathrm{REE}$ solution in $4 \mathrm{M} \mathrm{Cl}^{-}$medium were carried out.

The results show that the extraction percentages of $\mathrm{Tb}(\mathrm{III})$ and Dy(III) are similar throughout the entire $\mathrm{pH}$ range. However, $\mathrm{Nd}(\mathrm{III})$ shows an extraction behaviour completely different which can be harnessed to separate it from the mixture $(\mathrm{Nd} / \mathrm{Tb} / \mathrm{Dy})$. As can be seen in Fig. 5 a, the greater difference in the $\mathrm{Nd}(\mathrm{III})$ extraction compared to the other two REEs is obtained in the $0.8-1.5 \mathrm{pH}$ range.

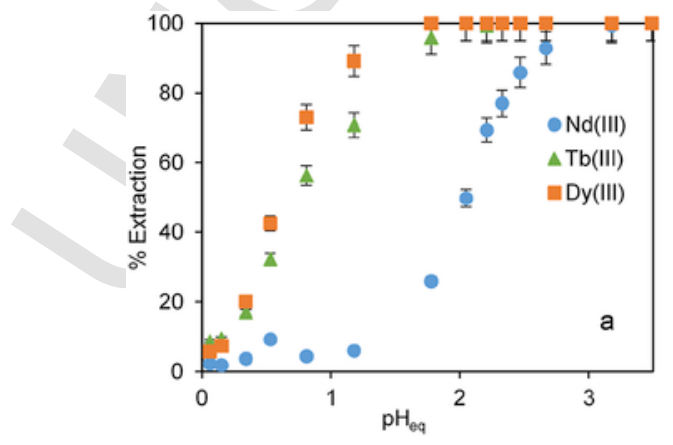

In order to confirm the mechanism described in Eq. (3), the plot of $p H_{e q}$ vs. $p H_{\text {initial }}$ for the $\mathrm{Nd} / \mathrm{Tb} / \mathrm{Dy}$ metals is presented in Fig. 5 b. The results indicate that there is no proton release when the REEs are extracted. As a consequence, the choice of using an ionic liquid like the P81R.Cy572 IL, in order to maintain the $\mathrm{pH}$ during the extraction process, is confirmed.

\subsubsection{Effect of Primene 81R concentration}

Being the objective to determinate the P81R/Cy572 ratio in the IL, in this section, a study has been done maintaining 0.30M of Cy572 and varying the P81R concentration from $0.09 \mathrm{M}$ up to $0.36 \mathrm{M}$. The diluent used was kerosene. The aqueous phase was $1 \mathrm{gdm}^{-3}$ of each REE in $4 \mathrm{M} \mathrm{Cl}^{-}$at an initial $\mathrm{pH} 0.10$. The higher the P81R concentration is in the IL, the bigger the extraction of REEs is as shown in Fig. 6. This is because when the P81R concentration increases, more IL is formed up to $0.30 \mathrm{M}(1: 1 \mathrm{M}$ ratio). However, the neodymium extraction increase is suppressed by the preferential loading of the two heavy REEs in the organic phase.

As shown in Table 4 , the $\beta_{\mathrm{Dy} / \mathrm{Nd}}$ values increase until achieving the maximum value, 86 , using $0.30 \mathrm{M}$ of both extractants (P81R and Cy572), then the separation factor decreases because the Dy(III) extraction is almost maintained, and the extraction of $\mathrm{Nd}(\mathrm{III})$ increases at higher P81R concentrations.

Taking into account that the neutral equivalent values of P81R and Cy572 are 191 and $310 \mathrm{~g} / \mathrm{mol}$, respectively (Table 1 ) and regarding Table 4 results, the maximum selectivity corresponds to an equimolar mixture of Cy572 and P81R, which also accords with the IL formation stoichiometry (Eq. (2)).

\subsubsection{Effect of IL concentration}

In order to investigate the effect of the P81R.Cy572 IL concentration on the extraction, experiments were performed varying the IL concentration from 0.10 up to $0.60 \mathrm{M}$. Kerosene was the diluent used. The aqueous phase was $1 \mathrm{~g} \mathrm{dm}^{-3}$ of each REE in $4 \mathrm{M} \mathrm{Cl}^{-}$fixing the initial $\mathrm{pH}$ at 0.10 . The extraction percentages of neodymium, terbium and dysprosium increase as the ionic liquid concentration increases (Fig. 7).

The equilibrium $\mathrm{pH}$ is maintained in the 1.19-1.25 range. This confirms that there are no protons exchange to the aqueous phase when the REEs are extracted with P81R.Cy572 IL (Eq. (3)). Additionally, taking into account the Padhan and Sarangi investigation where Pr and Nd were stripped with an efficiency of 98.11 and $98.75 \%$, respectively, using $1.8 \mathrm{M}$ of $\mathrm{H}_{2} \mathrm{SO}_{4}$ (Padhan and Sarangi, 2017), the $\mathrm{Nd}$ (III), Tb(III) and Dy(III) loaded in the organic phase was completely stripped using $\mathrm{HCl}$ $4 \mathrm{M}$.

The aforementioned experiment by Padhan and Sarangi, also suggests that three molecules of Aliquat 336.Cyanex 272 IL are involved in the solvent extraction of one molecule of neodymium and praseodymium (Padhan and Sarangi, 2017) and our results are in consonance with this study because the slope values of $\log D-3 \log \left[\mathrm{Cl}^{-}\right]$

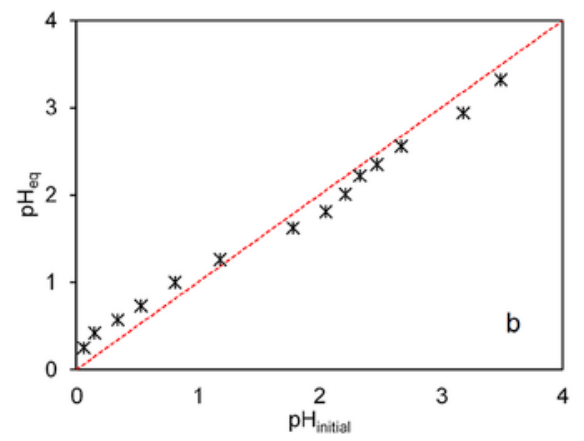

Fig. 5. a) Extraction of $1 \mathrm{gdm}^{-3}$ REEs in $4 \mathrm{M} \mathrm{Cl}^{-}$at different $\mathrm{pH}$ conditions using $0.30 \mathrm{M}$ P81R.Cy572 IL in kerosene (triplicate test). b) Plot of $p H_{e q}$ vs. $p H_{\text {initial }}$. 


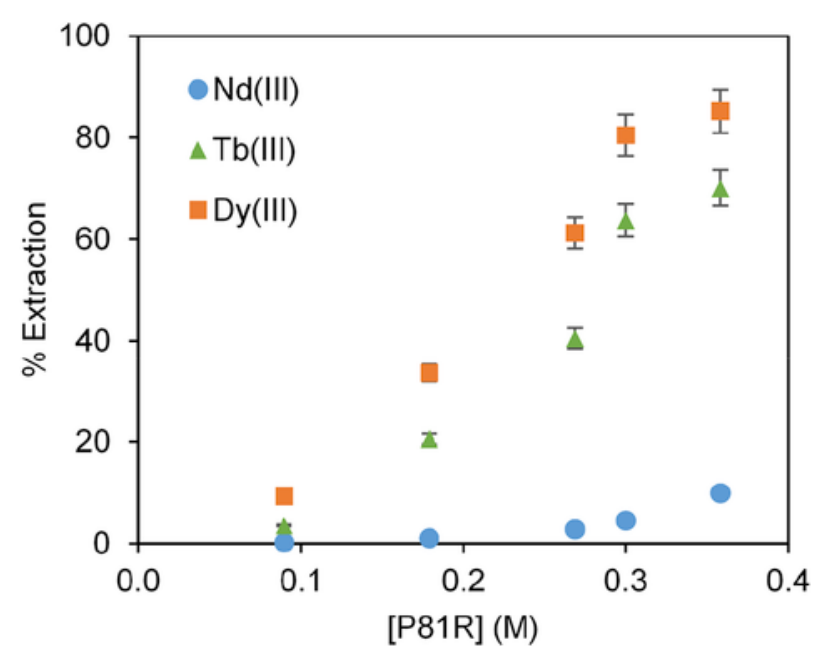

Fig. 6. Effect of P81R concentration keeping $0.30 \mathrm{M}$ of Cy572 in the P81R.Cy572 IL on REEs extraction using kerosene as diluent (triplicate test). Aqueous phase: $1 \mathrm{~g} \mathrm{dm}^{-3}$ of each metal solution in $4 \mathrm{M} \mathrm{Cl}^{-}$at initial $\mathrm{pH} 0.10$.

vs. $-\log [P 81 R \cdot C y 572 I L]$ are $3.03,2.74$ and 2.54 for neodymium, terbium and dysprosium, respectively (Fig. $\mathrm{S} 4$ in the supplementary material).

Keeping in mind that the objective is to separate $\mathrm{Nd}(\mathrm{III})$ from the $\mathrm{Nd} / \mathrm{Tb} / \mathrm{Dy}$ mixture, $0.30 \mathrm{M}$ of P81R.Cy572 IL is chosen, because using this IL concentration a higher selectivity is obtained (Table 5).

\subsubsection{Effect of the diluent to be used in the counter-current extraction}

Since kerosene is one of the most commonly utilized diluents due to its properties, it was mainly used in this investigation as a diluent. However, considering the possibility of the appearance of a third phase at a higher REEs organic phase loadings and with a higher $\mathrm{pH}_{\text {eq, }}$, it has been considered appropriate to investigate the effect of different diluents on the REEs extraction to be used in the counter-current extraction process. Although nowadays the use of aromatic diluents is not recommended, they can be utilized to avoid the third phase formation. Because of this, apart from the kerosene, toluene, cumene, Solvesso 100 and Solvesso 200 were the different aromatic diluents studied.

As a result, different extraction experiments using $0.30 \mathrm{M}$ of P81.Cy572 IL have been carried out. The aqueous phase contained the same REE concentrations that will be used in the counter-current experiments, 9.00, 0.50 and $2.50 \mathrm{gdm}^{-3}$ of Nd(III), Tb(III) and Dy(III), respectively, in $4 \mathrm{M} \mathrm{Cl}^{-}$. The results are shown in Table 6 where it can be observed that the diluent effect on the REEs extraction is not non-existent.

The dielectric constant was chosen as a key parameter since it allows us to get an idea of the polarity of the studied diluents. It was observed that the higher is the dielectric constant, the greater is the polarity of the diluent. Even if this parameter is different for the investigated diluents, the extraction percentages are very similar using all the used diluents. As a result, the polarity of the diluents studied has no influence on the neodymium, terbium and dysprosium extraction using 0.30 M P81R·Cy572 IL.
Taking into account the third phase formation restraining, Solvesso 100 was selected to be the diluent to make the counter-current extraction experiments.

\subsubsection{Counter-current experiment}

The REEs separation from a synthetic magnet waste solution sample which is considered equal to a real magnet waste sample, was carried out by the counter-current extraction process. The theoretical number of stages required to separate neodymium from the mixture using a counter-current system can be calculated if the extraction equilibria are known and solving the mass balance equations at all stages. Taking into account that the REE concentrations in magnet wastes are $\mathrm{Nd}(\mathrm{III})$ $\gg$ Dy(III) $>$ Tb(III) and the REEs affinity using P81R.Cy572 IL is Dy(III) $>\mathrm{Tb}(\mathrm{III}) \gg \mathrm{Nd}(\mathrm{III})$, the extraction isotherm study has been done referring to Dy(III).

The aqueous phase was a mixture of $9.00 \mathrm{gdm}^{-3}$ of $\mathrm{Nd}(\mathrm{III})$, $0.50 \mathrm{~g} \mathrm{dm}^{-3}$ of $\mathrm{Tb}(\mathrm{III})$ and a range of $\mathrm{Dy}(\mathrm{III})$ concentrations from 0.10 up to $2.55 \mathrm{~g} \mathrm{dm}^{-3}$, coincident with the real concentration of these REEs in the magnet wastes (Binnemans et al., 2013; Sasai and Shimamura, 2016; Yang et al., 2017). The IL concentration was $0.30 \mathrm{M}$ and Solvesso 100 was used as the diluent to avoid the third phase formation in the organic phase. The working conditions required an A:O ratio of 1:4.

The McCabe-Thiele plot (Fig. 8a) indicates that at least two stages are required to obtain the total elimination of Dy(III) from the aqueous phase at $\mathrm{A}: \mathrm{O}$ ratio of 1:4. Following the procedure established in Section 2.5 and as can also be seen in Fig. S5 (in the supplementary material), eleven contacts were necessary to achieve the steady-state concentrations in all the phases. The bold points shown in Fig. 8 a are the Dy(III) experimental concentrations obtained in the two counter-current stages after the system stabilisation. Bold points are close to the isotherm line and the differences can be explained because the initial $\mathrm{pH}$ was not exactly the same that the isotherm experiment.

Fig. $8 \mathrm{~b}$ shows the measured concentrations of $\mathrm{Nd}(\mathrm{III}), \mathrm{Tb}(\mathrm{III})$ and Dy(III) in each phase and for every step of the separation process in the counter-current extraction process. The equilibria $\mathrm{pH}$ for each stage is also shown. The $\mathrm{Tb}(\mathrm{III})$ and $\mathrm{Dy}(\mathrm{III})$ concentrations in the raffinate gradually decrease while the concentration of $\mathrm{Nd}(\mathrm{III})$ remains constant throughout the whole process, so there is not co-extraction of this LREE at these pHs. This can be explained by the HREEs preferential extraction over the LREEs. Conversely, terbium and dysprosium concentrations increase in the loaded organic solutions. Consequently, the main objective for using the P81R.Cy572 IL in the counter-current extraction experiment has been demonstrated because the $\mathrm{pH}$ during the extraction remained close to 1.2 .

Summing up, the counter-current process allows us to recover $99.99 \%$ of the neodymium with a purity of $99.7 \%$ maintaining the $\mathrm{pH}$ close to 1.2 without $\mathrm{pH}$ conditioning.

\section{Conclusions}

The P81R.Cy572 IL had been proposed as the extractant to recover neodymium from synthetic magnet waste leachings and its choice to be used in an industrial counter-current process has been successfully demonstrated.

Table 4

Separation studies of Dy/Nd and Tb/Nd using different concentration of P81R and maintaining 0.30M of Cy572 in the P81R.Cy572 IL.

\begin{tabular}{|c|c|c|c|c|c|c|}
\hline [Primene 81R] (M) & $\mathrm{pH}_{\mathrm{eq}}$ & $\mathrm{D}_{\mathrm{Nd}}$ & $\mathrm{D}_{\mathrm{Tb}}$ & $\mathrm{D}_{\text {Dy }}$ & $\beta_{\mathrm{Dy} / \mathrm{Nd}}$ & $\beta_{\mathrm{Tb} / \mathrm{Nd}}$ \\
\hline 0.09 & 0.17 & 0.00 & 0.04 & 0.10 & 41 & 15 \\
\hline 0.18 & 0.36 & 0.01 & 0.26 & 0.51 & 48 & 24 \\
\hline 0.27 & 0.72 & 0.03 & 0.68 & 1.58 & 54 & 23 \\
\hline 0.30 & 1.05 & 0.05 & 1.76 & 4.13 & 86 & 37 \\
\hline 0.36 & 1.16 & 0.11 & 2.34 & 5.75 & 52 & 21 \\
\hline
\end{tabular}




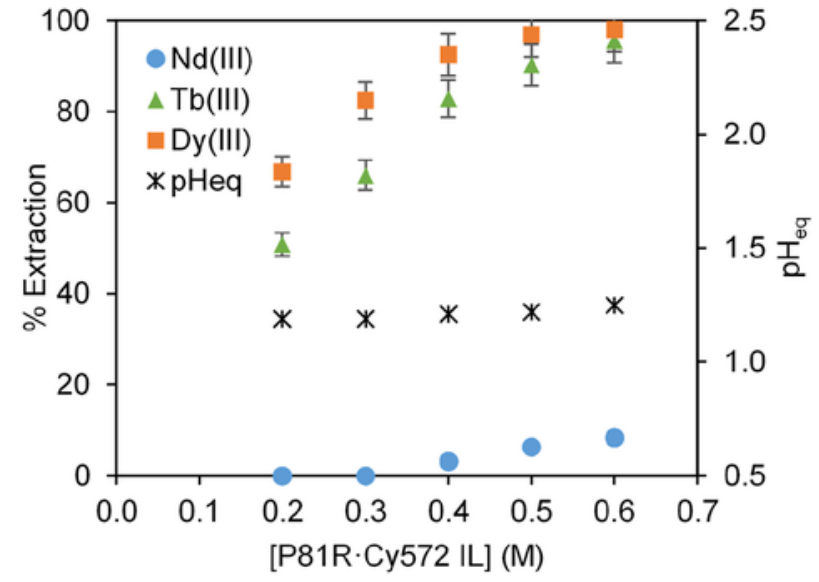

Fig. 7. Effect of P81R.Cy572 IL concentration on the REEs extraction at initial $\mathrm{pH} 0.10$ using kerosene as diluent (triplicate test). Aqueous phase: $1 \mathrm{~g} \mathrm{dm}^{-3}$ of each metal in $4 \mathrm{M}$ $\mathrm{Cl}^{-}$.

The $\mathrm{pH}$ dependence on REEs extraction was investigated, and the optimum range to achieve the separation goal is from 0.8 up to 1.5. The organic phase composition that allows, the separation of $\mathrm{Nd}(\mathrm{III})$ from the mixture with the highest selectivity is $0.30 \mathrm{M}$ of P81R:Cy572 (1:1 M ratio) in kerosene. It is possible to strip completely the $\mathrm{Nd}(\mathrm{III}), \mathrm{Tb}(\mathrm{III})$ and Dy(III) completely from the loaded organic phase by using a $4 \mathrm{M}$ $\mathrm{HCl}$ solution.
The study of the extraction mechanism of REEs using P81R.Cy572 IL by slope analysis suggests that three molecules of IL are involved in the solvent extraction of one molecule of Nd(III), Tb(III) and Dy(III).

The counter-current process results indicate that to separate $\mathrm{Nd}(\mathrm{III})$ from the mixture $\mathrm{Nd} / \mathrm{Tb} / \mathrm{Dy}$ using $0.30 \mathrm{M}$ of P81R.Cy572 IL and Solvesso 100 as the organic phase permits the elimination of $99.99 \%$ and $99 \%$ of the initial $\mathrm{Tb}(\mathrm{III})$ and $\mathrm{Dy}(\mathrm{III})$, respectively, while only working two stages without any aqueous $\mathrm{pH}$ conditioning. Thus, the $\mathrm{pH}$ remained constant around 1.2 during the extraction in the two counter-current process stages. This fact is the main claim of the current investigation in order to recover REEs using an industrial process.

\section{Acknowledgments}

This research was supported by the MINECO [grant numbers CTM2014-52770-R, CTM2017-83581-R].

We express our gratitude to Cytec Industries Inc., Dow Chemical and ExxonMobil for providing free samples of Cyanex 272, Cyanex 572, Primene 81R, Solvesso 100 and Solvesso 200.

\section{Appendix A. Supplementary data}

Supplementary data related to this article can be found at https:// doi.org/10.1016/j.jenvman.2018.05.054.

Table 5

Separation studies of Dy/Nd and Tb/Nd using different concentrations of P81R.Cy572 IL.

\begin{tabular}{|c|c|c|c|c|c|c|}
\hline [P81R.Cy572 IL] (M) & $\mathrm{pH}_{\mathrm{eq}}$ & $\mathrm{D}_{\mathrm{Nd}}$ & $\mathrm{D}_{\mathrm{Tb}}$ & $\mathrm{D}_{\mathrm{Dy}}$ & $\beta_{\mathrm{Dy} / \mathrm{Nd}}$ & $\beta_{\mathrm{Tb} / \mathrm{Nd}}$ \\
\hline 0.2 & 1.19 & 0.00 & 1.03 & 2.01 & 2580 & 1324 \\
\hline 0.3 & 1.19 & 0.00 & 1.94 & 4.70 & 6611 & 2732 \\
\hline 0.4 & 1.21 & 0.00 & 4.84 & 12.4 & 377 & 147 \\
\hline 0.5 & 1.22 & 0.07 & 9.26 & 30.7 & 452 & 136 \\
\hline 0.6 & 1.25 & 0.09 & 21.7 & 50.5 & 553 & 238 \\
\hline
\end{tabular}

Table 6

Effect of diluents on the extraction of $9.00,0.50$ and $2.50 \mathrm{~g} \mathrm{dm}^{-3}$ of $\mathrm{Nd}(\mathrm{III}), \mathrm{Tb}(\mathrm{III})$ and Dy(III) respectively using $0.30 \mathrm{M}$ of P81R.Cy572 IL.

\begin{tabular}{|c|c|c|c|c|c|c|}
\hline \multirow[t]{2}{*}{ Diluent category } & \multirow[t]{2}{*}{ Commercial name } & \multirow[t]{2}{*}{ Dielectric constant } & \multicolumn{3}{|l|}{ E\% } & \multirow[t]{2}{*}{ Third phase formation } \\
\hline & & & $\mathrm{Nd}$ & $\mathrm{Tb}$ & Dy & \\
\hline Aliphatic & Kerosene & 1.80 & 0.95 & 48.9 & 71.1 & Yes \\
\hline \multirow[t]{4}{*}{ Aromatic } & Cumene & 2.40 & 7.9 & 51.4 & 71.4 & Yes \\
\hline & Toluene & 2.36 & 7.4 & 47.2 & 66.5 & Yes \\
\hline & Solvesso 100 & $2-4.99$ & 3.1 & 46.0 & 67.8 & No \\
\hline & Solvesso 200 & & 2.9 & 48.8 & 67.9 & Yes \\
\hline
\end{tabular}




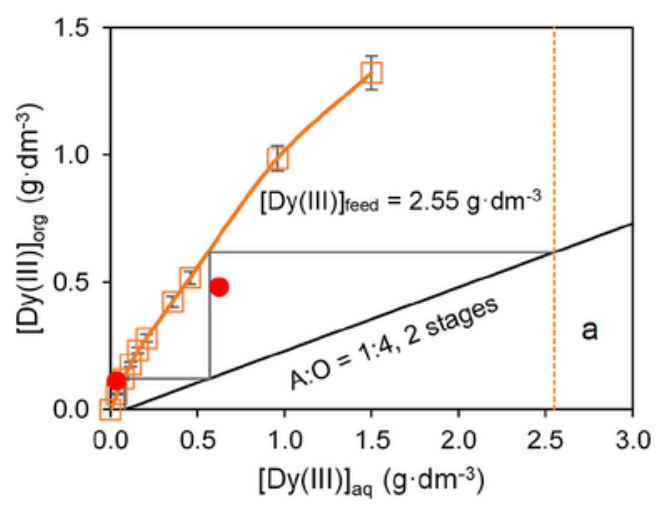

\begin{tabular}{|c|c|c|c|c|}
\hline \multicolumn{2}{|l|}{ Loaded organic } & & \multicolumn{2}{|r|}{ Organic phase } \\
\hline $\begin{array}{l}0.00 \mathrm{~g} \cdot \mathrm{dm}^{-3} \mathrm{Nd}(\mathrm{III}) \\
0.11 \mathrm{~g} \cdot \mathrm{dm}^{-3} \mathrm{~Tb}(\mathrm{III}) \\
0.62 \mathrm{~g} \cdot \mathrm{dm}^{-3} \mathrm{Dy}(\mathrm{III})\end{array}$ & \multicolumn{3}{|c|}{$\begin{array}{l}0.00 \mathrm{~g} \cdot \mathrm{dm}^{-3} \mathrm{Nd}(\mathrm{III}) \\
0.04 \mathrm{~g} \cdot \mathrm{dm}^{-3} \mathrm{~Tb}(\mathrm{III}) \\
0.15 \mathrm{~g} \cdot \mathrm{dm}^{-3} \mathrm{Dy}(\mathrm{III})\end{array}$} & $\begin{array}{l}0.00 \mathrm{~g} \cdot \mathrm{dm}^{-3} \mathrm{Nd}(\mathrm{III}) \\
0.00 \mathrm{~g} \cdot \mathrm{dm}^{-3} \mathrm{~Tb}(\mathrm{III}) \\
0.00 \mathrm{~g} \cdot \mathrm{dm}^{-3} \mathrm{Dy}(\mathrm{III})\end{array}$ \\
\hline$A: O=1: 4$ & 1 & & 2 & \\
\hline \multicolumn{2}{|l|}{$\begin{array}{l}9.00 \mathrm{~g} \cdot \mathrm{dm}^{-3} \mathrm{Nd}(\mathrm{III}) \\
0.50 \mathrm{~g} \cdot \mathrm{dm}^{-3} \mathrm{~Tb}(\mathrm{III}) \\
2.55 \mathrm{~g} \cdot \mathrm{dm}^{-3} \mathrm{Dy}(\mathrm{III})\end{array}$} & $\begin{array}{c}9.00 \mathrm{~g} \cdot \mathrm{dm}^{-3} \mathrm{Nd}(\mathrm{III}) \\
0.15 \mathrm{~g} \cdot \mathrm{dm}^{-3} \mathrm{~Tb}(\mathrm{III}) \\
0.62 \mathrm{~g} \cdot \mathrm{dm}^{-3} \mathrm{Dy}(\mathrm{III}) \\
\mathrm{pH} 1.20\end{array}$ & & $\begin{array}{l}9.00 \mathrm{~g} \cdot \mathrm{dm}^{-3} \mathrm{Nd}(\mathrm{III}) \\
0.00 \mathrm{~g} \cdot \mathrm{dm}^{-3} \mathrm{~Tb}(\mathrm{III}) \\
0.03 \mathrm{~g} \cdot \mathrm{dm}^{-3} \mathrm{Dy}(\mathrm{III})\end{array}$ \\
\hline Feed aqueous ph & & $\mathrm{pH} 1.20$ & & Raffinate \\
\hline
\end{tabular}

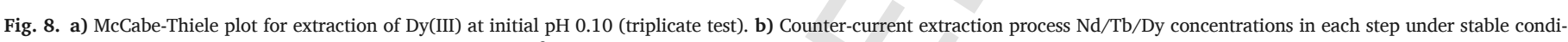
tions (feed pH 0.26). Aqueous phase: $9.00,0.50$ and $2.50 \mathrm{~g} \mathrm{dm}^{-3}$ of $\mathrm{Nd}(\mathrm{III})$, Tb(III) and Dy(III) respectively. Organic phase: $0.30 \mathrm{M}$ P81R.Cy572 IL in Solvesso 100.

\section{References}

Batchu, N.K., Vander Hoogerstraete, T., Banerjee, D., Binnemans, K., 2017. Non-aqueous solvent extraction of rare-earth nitrates from ethylene glycol to n-dodecane by Cyanex 923. Separ. Purif. Technol. 174, 544-553. https://doi.org/10.1016/j.seppur.2016.10. 039.

Binnemans, K., Jones, P.T., Blanpain, B., Van Gerven, T., Yang, Y., Walton, A., Buchert, M., 2013. Recycling of rare earths: a critical review. J. Clean. Prod. 51, 1-22. https:// doi.org/10.1016/j.jclepro.2012.12.037.

Chen, J., Huang, C., Wang, Y., Huang, B., Sun, X., 2016. Extraction behavior of bifunctional ionic liquid [N1888] [SOPAA] and TBP for rare earth elements. J. Rare Earths 34, 1252-1259. https://doi.org/10.1016/S1002-0721(16)60161-8.

Chen, Y., Wang, H., Pei, Y., Wang, J., 2017. Selective separation of scandium (III) from rare earth metals by carboxyl-functionalized ionic liquids. Separ. Purif. Technol. 178, 261-268. https://doi.org/10.1016/j.seppur.2017.01.058.

CYTEC Industries Inc., 2008. CYANEX 272 Extractant. Technical Brochure, Canada.

CYTEC Industries Inc., 2013. CYANEX 572 Extractant. Technical Brochure, Canada.

European Commission, 2014. Strengthening the European Rare Earths Supply-chain. 102.

Huang, Y., Tanaka, M., 2010. Solvent extraction equilibrium of dysprosium(III) from nitric acid solutions with 2-ethylhexylphosphonic acid mono-2-ethylhexyl ester. Trans. Nonferrous Metals Soc. China 20, 707-711. https://doi.org/10.1016/ S1003-6326(09)60202-8.

Larsson, K., Binnemans, K., 2015. Separation of rare earths by split-anion extraction. Hydrometallurgy 156, 206-214. https://doi.org/10.1016/j.hydromet.2015.04.020.

Liu, Y., Jeon, H.S., Lee, M.S., 2014. Solvent extraction of Pr and Nd from chloride solution by the mixtures of Cyanex 272 and amine extractants. Hydrometallurgy 150, 61-67. https://doi.org/10.1016/j.hydromet.2014.09.015.

Liu, Y., Jeon, H.S., Lee, M.S., 2015. Solvent extraction of Pr and Nd from chloride solutions using ternary extractant system of Cyanex 272, Alamine 336 and TBP. J. Ind. Eng. Chem. 31, 74-79. https://doi.org/10.1016/j.jiec.2015.06.009.

Mohammadi, M., Forsberg, K., Kloo, L., Martinez De La Cruz, J., Rasmuson, Ke, 2015. Separation of Nd(III), Dy(III) and Y(III) by solvent extraction using D2EHPA and EHEHPA. Hydrometallurgy 156, 215-224. https://doi.org/10.1016/j.hydromet.2015.05.004.

Padhan, E., Sarangi, K., 2017. Recovery of Nd and Pr from NdFeB magnet leachates with bi-functional ionic liquids based on Aliquat 336 and Cyanex 272. Hydrometallurgy 167, 134-140. https://doi.org/10.1016/j.hydromet.2016.11.008.

Panda, R., Jha, M.K., Hait, J., Kumar, G., Singh, R.J., Yoo, K., 2015. Extraction of lanthanum and neodymium from leach liquor containing rare earth metals (REMs). Hydrometallurgy 165, 106-110. https://doi.org/10.1016/j.hydromet.2015.10.019.

Pavon, S., Kutucu, M., Coll, M.T., Fortuny, A., Sastre, A.M., 2017. Comparison of Cyanex 272 and Cyanex 572 on the separation of neodymium from a Nd/Tb/Dy mixture by pertraction. J. Chem. Technol. Biotechnol. https://doi.org/10.1002/jctb.5458.
Quinn, J.E., Soldenhoff, K.H., Stevens, G.W., Lengkeek, N.A., 2015. Solvent extraction of rare earth elements using phosphonic/phosphinic acid mixtures. Hydrometallurgy 157, 298-305. https://doi.org/10.1016/j.hydromet.2015.09.005.

Rao, K.S.R., Sunderan, T., at Adiris, M.R., 2017. Performance and design optimization of two model based wave energy permanent magnet linear generators. Renew. Energy 101, 196-203. https://doi.org/10.1016/j.renene.2016.07.019.

Rare, A., Monthly, E., Market, M.R.E., Ree, C., 2015. Argus Rare Earths Monthly Outlook. $1-12$.

ROHM HA\&AS, 1961. Ind. Eng. Chem. 53, https://doi.org/10.1021/i650620a763, 80A-80A.

Sasai, R., Shimamura, N., 2016. Technique for recovering rare-earth metals from spent sintered Nd-Fe-B magnets without external heating. J. Asian Ceram. Soc. 4, 155-158. https://doi.org/10.1016/j.jascer.2016.01.009.

Schulze, R., Buchert, M., 2016. Estimates of global REE recycling potentials from NdFeB magnet material. Resour. Conserv. Recycl. 113, 12-27. https://doi.org/10.1016/ j.resconrec.2016.05.004.

Smith Stegen, K., 2015. Heavy rare earths, permanent magnets, and renewable energies: an imminent crisis. Energy Pol. 79, 1-8. https://doi.org/10.1016/j.enpol.2014.12. 015 .

Tsamis, A., Coyne, M., 2015. Recovery of Rare Earths from Electronic Wastes: an Opportunity for High-tech SMEs.

Tunsu, C., Petranikova, M., Gergorić, M., Ekberg, C., Retegan, T., 2015. Reclaiming rare earth elements from end-of-life products: a review of the perspectives for urban mining using hydrometallurgical unit operations. Hydrometallurgy 156, 239-258. https: //doi.org/10.1016/j.hydromet.2015.06.007.

Tunsu, C., Lapp, J.B., Ekberg, C., Retegan, T., 2016. Selective separation of yttrium and europium using Cyanex 572 for applications in fluorescent lamp waste processing. Hydrometallurgy 166, 98-106. https://doi.org/10.1016/j.hydromet.2016.10.012.

U.S. Department of Energy, 2012. U.S. Department of Energy: Critical Materials Strategy, DOE/PI-0009.

Wang, Y., Li, F., Zhao, Z., Dong, Y., Sun, X., 2015. The novel extraction process based on CYANEX 572 for separating heavy rare earths from ion-adsorbed deposit. Separ. Purif. Technol. 151, 303-308. https://doi.org/10.1016/j.seppur.2015.07.063.

Wang, Y., Huang, C., Li, F., Dong, Y., Sun, X., 2017. Process for the separation of thorium and rare earth elements from radioactive waste residues using Cyanex® 572 as a new extractant. Hydrometallurgy 169, 158-164. https://doi.org/10.1016/j.hydromet. 2017.01.005.

Yang, Y., Walton, A., Sheridan, R., Güth, K., Gauß, R., Gutfleisch, O., Buchert, M., Steenari, B.-M., Van Gerven, T., Jones, P.T., Binnemans, K., 2017. REE recovery from end-of-life NdFeB permanent magnet scrap: a critical review. J. Sustain. Metall. 3, 122-149. https://doi.org/10.1007/s40831-016-0090-4. 